\title{
Use and Optimization of a Dual-Flowrate Loading Strategy To Maximize Throughput in Protein-A Affinity Chromatography
}

\author{
Sanchayita Ghose, ${ }^{\dagger}$ Deepak Nagrath, ${ }^{\ddagger}$ Brian Hubbard, ${ }^{\dagger}$ Clayton Brooks, ${ }^{\dagger}$ and \\ Steven M. Cramer*,
}

Purification Process Development, Amgen Inc., Seattle, Washington, and Department of Chemical \& Biological Engineering, Rensselaer Polytechnic Institute, Troy, New York 12180

\begin{abstract}
The effect of an alternate strategy employing two different flowrates during loading was explored as a means of increasing system productivity in Protein-A chromatography. The effect of such a loading strategy was evaluated using a chromatographic model that was able to accurately predict experimental breakthrough curves for this Protein-A system. A gradient-based optimization routine is carried out to establish the optimal loading conditions (initial and final flowrates and switching time). The two-step loading strategy (using a higher flowrate during the initial stages followed by a lower flowrate) was evaluated for an $\mathrm{F} \mathrm{c}$-fusion protein and was found to result in significant improvements in process throughput. In an extension of this optimization routine, dynamic loading capacity and productivity were simultaneously optimized using a weighted objective function, and this result was compared to that obtained with the single flowrate. Again, the dual-flowrate strategy was found to be superior.
\end{abstract}

\section{Introduction}

Monoclonal antibodies have emerged as an important and rapidly expanding class of drugs for the treatment of several human diseases. Approximately $30 \%$ of biopharmaceuticals currently in clinical trials are antibodies and F c-fusion proteins (1). Given the large scale at which many of these antibodies are produced (hundreds of kilograms/year), it is no surprise that the commercial success of these biomolecules hinges on the devel opment of efficient and economic downstream processes.

Protein-A affinity chromatography has come to be used routinely in industry for the direct capture and purification of monoclonal antibodies and $\mathrm{F}$ c-fusion proteins from complex cell culture media (2-4). The large mass requirements of antibodies coupled with the high cost of Protein-A media have made binding capacity and throughput on Protein-A primary concerns because they govern process economics in commercial scale purification processes.

The development of a Protein-A affinity chromatography process typically involves consideration of several factors. Many commercial Protein-A media are available that vary with respect to their backbone matrix, bead and pore size and the source of the Protein-A ligand. Typically, choice of the Protein-A resin depends on the best compromise between loading capacity, eluate purity and flow characteristics of the stationary phase. For a particular stationary phase, efforts are often made to maximize dynamic capacity in order to allow efficient and maximal utilization of the expensive Protein-A media. Typically, Protein-A media have a finite lifetime defined in terms of the maximum number of column reuses that

* To whom all correspondence should be addressed. Phone: (518) 276-6198. Email: crames@rpi.edu.

+ Amgen Inc.

‡ Rensselaer Polytechnic Institute. are possible. Given the finite lifetime, increasing the dynamic loading capacity on the col umn reduces the resin cost per unit quantity of antibody purified.

Another important consideration in bioprocessing is production rate or throughput $(5,6)$. Production rate can be especially important for Protein-A chromatography. Because the media is very expensive, rather than using a large column to process a batch of antibody in a single cycle, typical bioprocess applications run a smaller column for several cycles to purify a single batch. This reduces the risk of capital cost if the column is compromised during operation and also brings the column diameter into a practical range. Cycling increases the total purification time and thereby decreases the production rate. Thus, processing time can be an important factor in Protein-A step development. Fahrner et al. (7) discuss the importance of considering the optimal flowrate on Protein-A and suggest that higher flowrates will reduce process time without significantly affecting process capacity. Processing time has been mentioned to be critical to process development for three reasons (8). First, if purification is the limiting factor in a production facility, then a direct improvement in process time will increase throughput. Often, Protein-A is the first capture step and is often the rate-limiting step as a result of the large volume loads and low protein concentrations associated with the process. Second, the product stability in the harvested cell culture fluid can limit allowable hold and processing times. Third, cell culture fluid is a rich medium that can promote an increase in bioburden. Minimizing processing time can help to decrease bioburden contamination. The authors (8) even suggest using a resin with a slightly lower binding capacity but better flow characteristics to enable a decrease in the overall processing time.

Fahrner et al. (6) have compared the performance of several Protein-A resins using both volumetric (amount of protein purified per unit time per unit column volume) 
and actual production rates under different flowrates for these resins. Shukla et al. (9) have further extended this comparison by including a consideration of pressure drop at higher velocities, resin cost and the impact of col umn cycling. However, all these authors have used an empirical relationship to capture the effect of variation of dynamic capacity with flowrate instead of a masstransport model. There have been a few references in the literature dealing with equilibrium and transport parameters that govern binding in Protein-A systems. Horstmann and Chase (10) have modeled the affinity adsorption of immunoglobulin $\mathrm{G}$ to agarose based Protein-A media. The authors have shown that mass transfer in these systems can be well described by a combination of surface film resistance and intraparticle diffusion resistance. Mass transport parameters determined in stirred tank uptake experiments were used to predict performance in packed bed systems. Montesinos et al. (11) have also used a similar model to perform a parametric analysis of a batch affinity adsorption system. Recently, McCue et al. (12) have used the surface layer model (with mass transfer at the particle core described either by the homogeneous diffusion model or by the pore diffusion model) to compare the equilibrium and transport characteristics of two different Protein-A media having the same porous glass backbone but different pore sizes.

Several references in the literature $(13,14)$ describe the optimization of chromatographic separations using simplex-based techniques with a variety of objective functions (including production rate, yield and combinations of these). Luo and $\mathrm{H}$ su (15) used an iterative scheme to optimize the gradient slope in linear ion-exchange chromatography. In addition, iterative optimization schemes have been used for optimizing step gradient (16), linear gradient (17) and displacement systems (18). Suwondo et al. (19) employed a generalized reduced gradient method to maximize throughput in ideal linear chromatography. All of these approaches generally involve optimization of a single variable at a time. Recently, Nagrath et al. (20) have used a Sequential Quadratic Programming (SQP) al gorithm to maximize the objective function of production rate times yield (in the presence of solubility and purity constraints) for binary and tertiary protein systems. This al gorithm reduces computational time and enables multivariable optimization for optimal design of chromatographic separations.

Conventionally, a single flowrate is used to load the entire dilute feedstock onto Protein-A columns in industrial processes. For large volumes of cell-culture fluid, this makes the load time a significant proportion of the total cycle time for Protein-A processes. An alternative strategy to maximize throughput would be to vary the flowrate during the loading step (21). Intuitively, in the initial stages of column loading when all the binding sites are available one should be able to flow at a faster flowrate. Once all the readily accessible sites are blocked, a slower flowrate could then be used to enable the protein to diffuse into all the pores and bind to the less readily accessible sites. Although this approach has been proposed and verified by a few experiments with a model protein (21), this effect has not been studied in detail or optimized using theoretical models.

This paper evaluates the effect of such a two-step loading strategy by means of a mass transport model that is shown to accurately predict breakthrough curves in Protein-A systems. The combination of flowrates used for loading are then optimized using productivity and a weighted combination of productivity and capacity as objective functions. The results from this optimization then are compared to similarly optimized operating conditions for a single loading flowrate. The dual-flowrate loading strategy developed in this work resulted in a significant improvement in process throughput for the industrial purification of an Fc-fusion protein.

\section{Theory}

Equilibrium. Equilibrium in affinity systems can be modeled using a Langmuir isotherm, which is expressed by

$$
q^{*}=\frac{q_{0} b^{*}}{1+b C^{*}}
$$

Explanations of all terms are given in the Notation section.

Uptake Kinetics. The homogeneous diffusion model $(22,23)$ was used in this study to describe protein transport within the particle. According to this model, mass transfer is assumed to be affected by two resistances in series: the external film resistance and the intraparticle mass transfer resistance. For the case of Protein-A media, it has been shown that intraparticle diffusion and film mass transfer govern the overall mass transfer resistance, while contribution from reaction kinetics is not significant $(10,12)$. The following set of conservation equations and boundary conditions can be written to relate these two transport resistances to the experimental batch uptake kinetics.

For the particles:

$$
\begin{gathered}
\frac{\partial q}{\partial t}=\frac{D_{s}}{r^{2}} \frac{\partial}{\partial r}\left(r^{2} \frac{\partial q}{\partial r}\right) \\
r=0, \quad \frac{\partial q}{\partial r}=0 \\
r=R_{p}, \quad D_{s} \frac{\partial q}{\partial r}=k_{f}\left(C-C_{i}\right) \\
t=0, \quad q=0
\end{gathered}
$$

For the solution:

$$
\begin{gathered}
\frac{d C}{d t}=-\frac{3 k_{f}}{R_{p}} \frac{V_{M}}{V}\left(C-C_{i}\right)=-\frac{V_{M}}{V} \frac{d \bar{q}}{d t} \\
t=0, \quad C=C_{0}
\end{gathered}
$$

where $\bar{q}$ is the average solute concentration in the particle. Equilibrium can be assumed to exist at the particle-fluid interface.

The relative importance of external and intraparticle mass transfer is strongly dependent on solution concentration. Fernandez and Carta (24) have shown that a simple criterion is available to determine the controlling resistance in terms of the dimensionless group $\delta(25)$, which is given as

$$
\delta=\frac{1}{5} \frac{\mathrm{k}_{\mathrm{f}} \mathrm{R}_{\mathrm{p}}}{\mathrm{D}_{\mathrm{s}}} \frac{\mathrm{C}_{0}}{\mathrm{q}_{0}}
$$

When $\delta \ll 1$, external film mass transfer is dominant. In that case, protein concentration at the particle surface is negligibly small and the uptake rate is proportional to the bulk fluid phase solution concentration. Conversely, when $\delta \gg 1$, intraparticle mass transfer resis- 
tance is dominant. Under these conditions, as the uptake isotherm is highly favorable, the protein concentration at the particle surface is nearly constant and equal to the saturation capacity. The uptake rate can then be assumed to be practically independent of the bulk fluid phase concentration. Even though this criterion is not rigorous, it has been used to simplify the determination of $D_{s}$ and $k_{f}$ by considering experimental conditions leading to the two asymptotic cases of external film and intraparticle mass transfer control (24). This can be attained in the stirred batch experiments by operating with very low and very high protein concentrations. The limiting solution at high concentration (which is in the diffusion controlled regime) is given as $(25,26)$

$$
\frac{\bar{q}}{q_{0}} \sim\left\{1-\exp \left\{\pi^{2}\left[-\tau+0.960 \tau^{2}-2.92 \tau^{3}\right]\right\}\right\}^{1 / 2}
$$

where $\tau=\mathrm{D}_{\mathrm{s}} \mathrm{t} / \mathrm{R}_{\mathrm{p}}{ }^{2}$. This approach is used in this paper to determine the intraparticle diffusion parameter of the protein.

The value of the film mass transfer coefficient $\left(k_{f}\right)$ at different velocities was estimated using the following correlation (27):

$$
\mathrm{k}_{\mathrm{f}}=\frac{\mathrm{D}_{\mathrm{m}}}{\mathrm{d}_{\mathrm{p}}}\left[2+1.45\left(\frac{\mathrm{u}_{\mathrm{s}} \rho \mathrm{d}_{\mathrm{p}}}{\mu}\right)\left(\frac{\mu}{\rho \mathrm{D}_{\mathrm{m}}}\right)^{1 / 3}\right]
$$

The value of molecular diffusivity $\left(D_{m}\right)$ of the $F$ c-fusion protein was obtained from well-established correlation (28).

Column Behavior. The differential mass-balance equation in the column can be written as

$$
\epsilon \frac{\partial \mathrm{C}}{\partial \mathrm{t}}+(1-\epsilon) \frac{\partial \overline{\mathrm{q}}}{\partial \mathrm{t}}+\mathrm{u} \frac{\partial \mathrm{C}}{\partial \mathrm{z}}=\epsilon \mathrm{D}_{\mathrm{a}} \frac{\partial^{2} \mathrm{C}}{\partial \mathrm{z}^{2}}
$$

The shape of the breakthrough curve is thus determined by the equilibrium isotherm (eq 1), transport within the particle (eq 2), film mass transfer (eqs $2 \mathrm{~b}$ and 3 ) and deviations from plug-flow in the column (eq 7). In general, a numerical solution is required for an exact prediction of these effects on the column effluent profiles. However, for certain limiting forms of the isotherm, such as linear or rectangular, analytic expressions for the breakthrough curve can be employed (29). For their approximate analytical solution, Yoshida et al. (29) have neglected axial dispersion and have used the linear driving force approximation to describe intraparticle mass transfer. Under constant pattern conditions for a rectangular isotherm, when $\delta \geq 1$ the analytical solution for the profile of the breakthrough curve is given by

$$
\begin{aligned}
& \frac{\mathrm{C}}{\mathrm{C}_{0}}=\frac{1}{\delta} \exp \left(\tau-\xi+\delta-1-\frac{1}{\partial}\right) \\
& \qquad \text { for } \tau-\xi \leq-\delta+1+\frac{1}{\delta}-\ln \left(\frac{1+\delta}{\delta}\right)
\end{aligned}
$$

$$
\begin{array}{r}
\frac{\mathrm{C}}{\mathrm{C}_{0}}= \\
\quad 1-\frac{\delta}{1+\delta} \exp \left\{\frac{-\tau+\xi-\delta+1+\frac{1}{\delta}-\ln \left(\frac{1+\delta}{\delta}\right)}{\delta}\right\} \\
\quad \text { for } \tau-\xi \geq-\delta+1+\frac{1}{\delta}-\ln \left(\frac{1+\delta}{\delta}\right)
\end{array}
$$

and when $\delta \leq 1$ by

$$
\begin{gathered}
\frac{\mathrm{C}}{\mathrm{C}_{0}}=\exp (\tau-\xi-1) \text { for } \tau-\xi \leq 1-\ln (1+\delta) \\
\frac{\mathrm{C}}{\mathrm{C}_{\mathrm{o}}}=1-\frac{\delta}{1+\delta} \exp \left\{\frac{-\tau+\xi+1-\ln (1+\delta)}{\delta}\right\} \\
\text { for } \tau-\xi \geq 1-\ln (1+\delta)
\end{gathered}
$$

In these equations

$$
\begin{gathered}
\delta=\frac{1}{5} \frac{\mathrm{k}_{\mathrm{f}} \mathrm{R}_{\mathrm{p}}}{\mathrm{D}_{\mathrm{s}}} \frac{\mathrm{C}_{0}}{\mathrm{q}_{0}} \\
\tau=\frac{3 \mathrm{k}_{\mathrm{f}}}{\mathrm{R}_{\mathrm{p}}} \frac{\mathrm{C}_{0}}{\mathrm{q}_{0}}\left(\mathrm{t}-\frac{\epsilon \mathrm{L}}{\mathrm{u}}\right) \\
\xi=\frac{3(1-\epsilon)}{\mathrm{R}_{\mathrm{p}}} \frac{\mathrm{k}_{\mathrm{f}} \mathrm{L}}{\mathrm{u}}
\end{gathered}
$$

The analytical solution was used in this paper for the sake of simplicity and computati onal speed during optimization.

Productivity

In this paper, productivity or volumetric production rate is defined as the mass of protein purified in one cycle divided by the processing time taken, divided by the column volume to make it independent of scale (6):

$$
\text { productivity }(P)=\frac{\frac{\text { mass of product }}{\text { column volume }}}{\text { time }}=\frac{\frac{\mathrm{VQ}_{\mathrm{d}}}{\mathrm{V}}}{\frac{\mathrm{VQ}_{\mathrm{d}}}{\mathrm{C}_{0} \mathrm{U}_{\mathrm{L}} \mathrm{A}}+\frac{\mathrm{NV}}{\mathrm{U}_{\mathrm{N}} \mathrm{A}}}
$$

Rearranging terms, eq 10 reduces to

$$
P=\frac{1}{L\left(\frac{1}{C_{0} u_{L}}+\frac{N}{Q_{d} u_{N}}\right)}
$$

In this paper, we are employing a dual-flowrate loading strategy where the flowrate is changed from $u_{1}$ to $u_{2}\left(u_{1}\right.$ $>\mathrm{u}_{2}$ ) at time $\mathrm{t}_{\mathrm{seg}}$ during loading. In that case, total time taken for loading can be calculated as

time for load $=$

$$
t_{s e g}+\frac{\left(\frac{Q_{d} V}{C_{0}}-u_{1} A t_{s e g}\right)}{u_{2} A}=t_{s e g}+\frac{\left(\frac{Q_{d} L}{C_{0}}-u_{1} t_{s e g}\right)}{u_{2}}
$$

Productivity in that case will be defined as

$$
P=\frac{Q_{d}}{t_{s e g}+\frac{\left(\frac{Q_{d} L}{C_{0}}-u_{1} t_{s e g}\right)}{u_{2}}+\frac{N L}{u_{N}}}
$$

Optimization. To accomplish any optimization in preparative chromatographic systems, one needs to consider four different factors: objective function, parameters, decision variables and constraints (17). Optimization consists of maximizing or minimizing a given objective function. For the dual-flowrate case, an optimization routine has been employed to maximize productivity (defined by eq 13) with respect to three inde- 
pendent decision variables (i.e., the variables that are changed during optimization), $\mathrm{u}_{1}, \mathrm{u}_{2}$ and $\mathrm{t}_{\text {seg. }}$. At any point, the dynamic capacity $\left(Q_{d}\right)$ will be a function of $u_{1}$, $\mathrm{u}_{2}$ and $\mathrm{t}_{\mathrm{seg}}$ and can be determined using the analytical solution given above. For the single-flowrate case, the expression for objective function was simplified to that shown in eq 11. In addition, a weighted combination of capacity and productivity $\left(\mathrm{F}_{\mathrm{obj}}\right)$ as defined by eq 14 was also used as an objective function to address the conflicting demands of simultaneously high capacity and throughput.

$$
F_{o b j}=w_{1} P+w_{2} Q_{d}
$$

where

$$
w_{1}+w_{2}=1
$$

Parameters are conditions that cannot be changed during the optimization process. The remaining terms in eqs 13 and 11 can be assumed to be constant for a particular manufacturing case study and were the parameters used in this optimization work. The values of these parameters used were $\mathrm{L}=25 \mathrm{~cm}, \mathrm{C}_{0}=0.5 \mathrm{~g} / \mathrm{L}$; N $=10$ (for large scale column operation, it was assumed 2.5 column volumes equilibration, 3 column volumes wash, 3 column volumes elution, 1.5 column volumes strip); however, this strategy can be extended for any col umn length, load concentration, and value of $\mathrm{N}$.

Constraints define the region of the operating space in which the optimization process can be carried out. The physical constraint that was applied in this case was the maximum value of operating fl owrate $\left(u\right.$ or $\left.u_{1}, u_{2}\right)$, which was fixed according to the manufacturer's recommendation taking into consideration the pressure-drop limitations of the stationary phase. In addition, for the dualflowrate case, the value of $t_{\text {seg }}$ (i.e., the time of switch) has to be before $5 \%$ breakthrough occurs (since further loading would be discontinued in most industrial processes). Mathematically, this means that the second term in the denominator of eq 13 cannot be negative. Hence the constraint

$$
\frac{Q_{d} L}{C_{0}}>u_{1} t_{s e g}
$$

Various constrained optimization techniques were initially evaluated for maximizing productivity and dynamic loading capacity for the single and dual/segmented flowrate operating strategies. Since the problem is highly nonlinear and multivariable (initial flowrate, final flowrate and switching time) a Sequential Quadratic Programming (SQP) al gorithm (20) was found to be the most suitable. To ensure the global optimality of the obtained optimal solutions using the Levenberg-Marquardt scheme, optimization was performed with various initial conditions. Essentially, we varied the initial approximate solution throughout the design space so that the obtained optimal solution is global optimal.

\section{Experimental Section}

Materials. The recombinant Fc-fusion protein used in this study was expressed in $\mathrm{CHO}$ cells and produced at Amgen (Seattle, WA). Direct cell culture fluid (cell and cell debris removed by tangential flow filtration) was used as the load material for all experiments. Concentration of the recombinant protein in the harvest fluid was $\sim 0.5$ $\mathrm{mg} / \mathrm{mL}$.

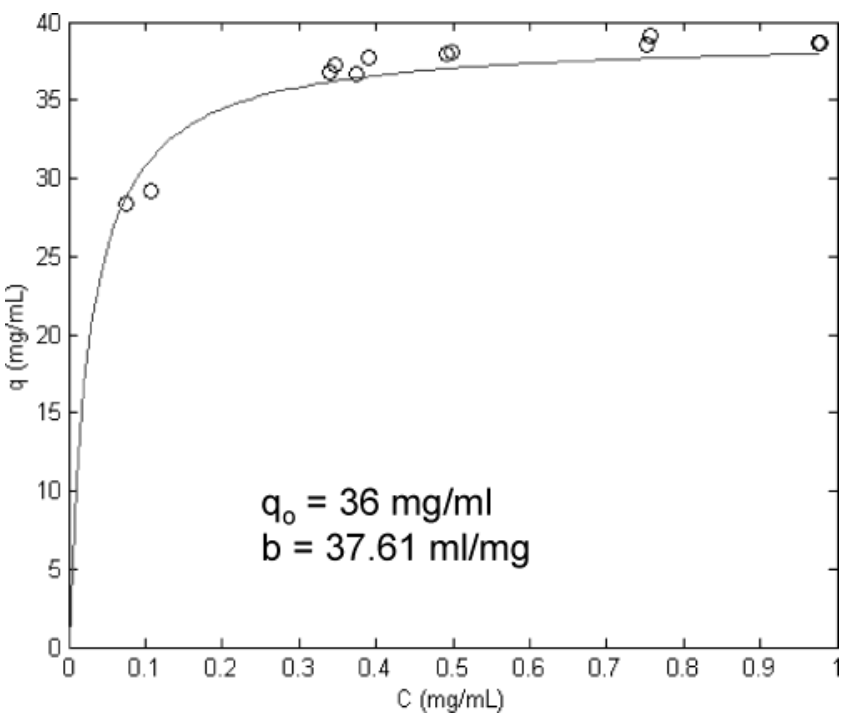

Figure 1. Adsorption equilibrium data in a $25 \mathrm{mM}$ Tris- $\mathrm{HCl}$ buffer at $\mathrm{pH}$ 7.4. Lines are calculated using the Langmuir isotherm (eq 1) using the parameters listed in the figure.

MabSelect (a Protein-A media on a hardened agarose matrix introduced lately for higher throughput purification of monoclonal antibodies) was obtained from Amersham Bi osciences (Piscataway, NJ ). A particle diameter of $85 \mu \mathrm{m}$ (obtained from the manufacturer) was used in this paper for all calculations. All media were packed in Vantage columns obtained from Millipore Corporation (Bedford, MA). POROS Protein-A col umns (2.1 mm $\times 30$ $\mathrm{mm}$ ) used for the analytical quantitation assay were obtained from PE Biosystems (Framingham, MA).

All buffer chemicals (Tris-base, tris- $\mathrm{HCl}$, sodium chloride, sodium citrate, citric acid, phosphoric acid, urea) used in this study was purchased from J T Baker (Phillipsburg, NJ)

Equipment. All dynamic capacity experiments were carried out on an AKTA Explorer chromatographic system from Amersham Biosciences (U ppsala, Sweden). HPLC analysis was carried out using a Waters (Milford, MA) HPLC 2690 separation module.

All simulations and optimization work were done by writing programs using a Matlab software platform obtained from The Mathworks Inc. (Natick, MA).

Methods. Determination of Equilibrium Parameters. The adsorption isotherm for the protein was determined using batch experiments. A slurry of the resin was made with the equilibration buffer $(25 \mathrm{mM}$ Tris, $\mathrm{pH}$ 7.4 with $100 \mathrm{mM} \mathrm{NaCl}$ ) in a 1:1 v/v ratio The cell-culture fluid was initially concentrated or diluted with the equilibration buffer (as was required) to obtain concentrations of the $\mathrm{Fc}$-fusion protein varying from 0.1 to 2.0 $\mathrm{mg} / \mathrm{mL}$. In all the experiments, $4 \mathrm{~mL}$ of the cell culture fluid (containing a known concentration of the protein) was contacted with $0.2 \mathrm{~mL}$ of the slurry media. The system was rotated on an orbital shaker for $24 \mathrm{~h}$ at room temperature. After equilibrium was reached, the concentration of the protein in the supernatant was determined by a HPLC Protein-A assay used for quantification. The amount of protein adsorbed by the media was then obtained from a mass balance. The adsorption isotherm data was used to fit $q_{0}$ and $b$ in eq 1 .

Determination of Transport Parameters. Protein uptake kinetics data was determined from stirred tank experiments similar to that described elsewhere $(12,22)$. Cell culture fluid $(\sim 500 \mathrm{~mL})$ containing known concentration of the protein (ca. $0.5-3.0 \mathrm{mg} / \mathrm{mL}$ ) was placed in 
(a)

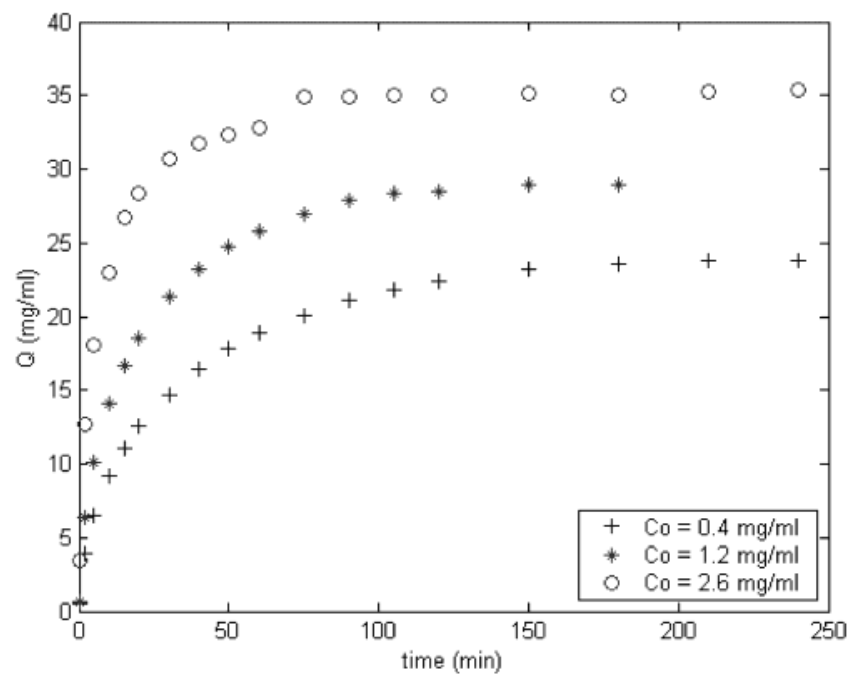

(b)

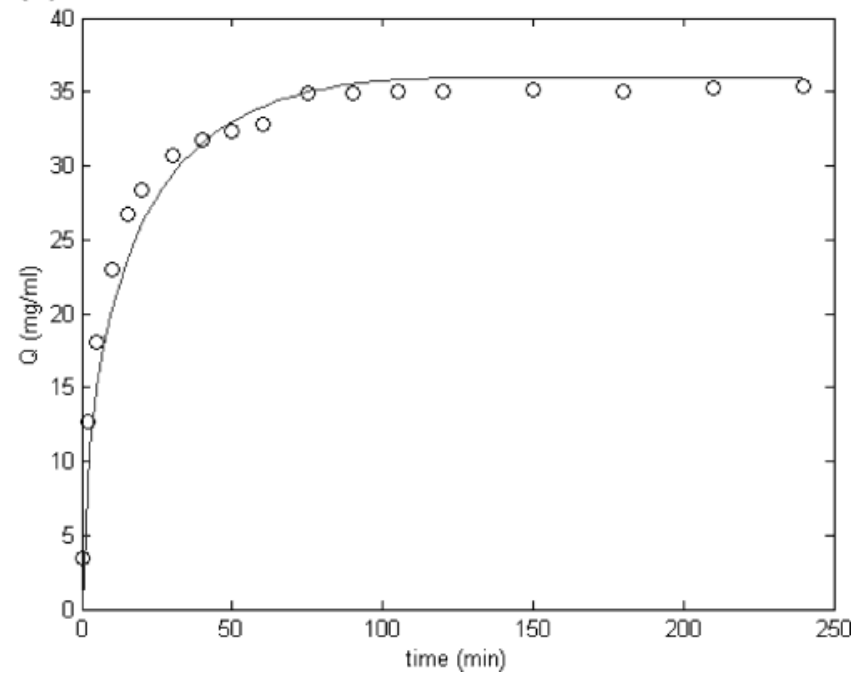

Figure 2. (a) Transient uptake data from stirred tank experiments using different initial protein concentrations $\left(\mathrm{C}_{0}\right)$. (b) Fit of the experimental data at $\mathrm{C}_{0}=2.6 \mathrm{mg} / \mathrm{mL}$ using eq 7 .

a beaker and stirred using a 5-cm long suspended stir bar at $100 \mathrm{rpm}$. Samples of ca. 5-20 mL of media were injected into the stirred solution. The concentration of protein in the solution over time was measured by continuously recirculating a small stream of the solution. Approximately $200 \mu \mathrm{L}$ of the sample was filtered through a $0.22-\mu \mathrm{m}$ syringe filter for subsequent protein analysis, and the rest of the stream was returned to the main bulk solution. The total response time of the circulation loop was $\sim 15 \mathrm{~s}$. The reduction in volume due to the samples withdrawn for analysis was negligible.

Breakthrough Curve Generation. For all frontal experiments, the chromatographic column was sequentially perfused with equilibration buffer (4 column volumes), feed load, wash (4 column volumes), elution (4 column volumes) and regeneration buffers ( 3 column volumes). Column effluent fractions ( 1 column volume) were collected during the loading step, and the protein concentration in each fraction was determined using the HPLC Protein-A assay. Protein concentration was plotted against column loading, and dynamic capacity was calculated at 5\% breakthrough. The column was equilibrated with $25 \mathrm{mM}$ Tris (pH 7.4) with $100 \mathrm{mM} \mathrm{NaCl}$, and the bound protein was eluted using $100 \mathrm{mM} \mathrm{NaCl}$ (a)

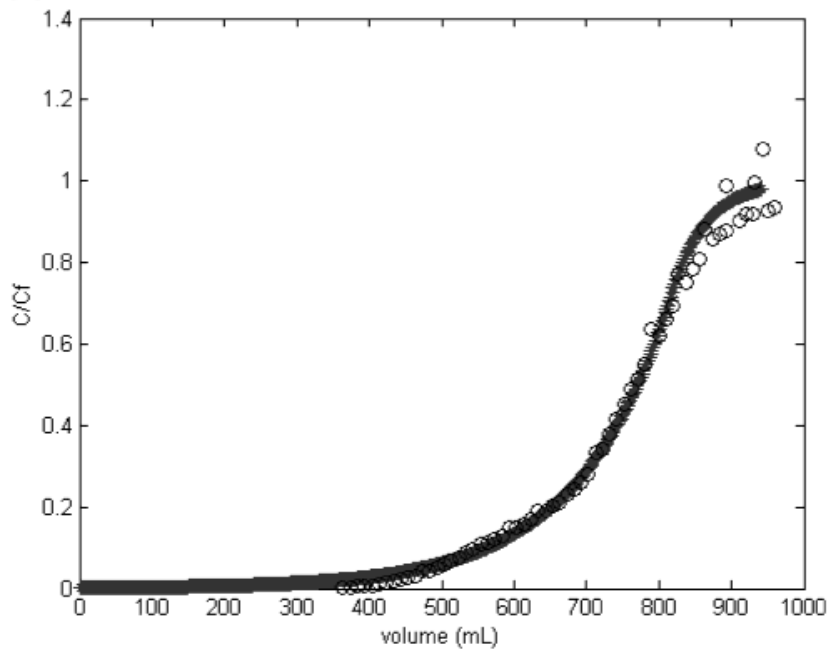

(b)

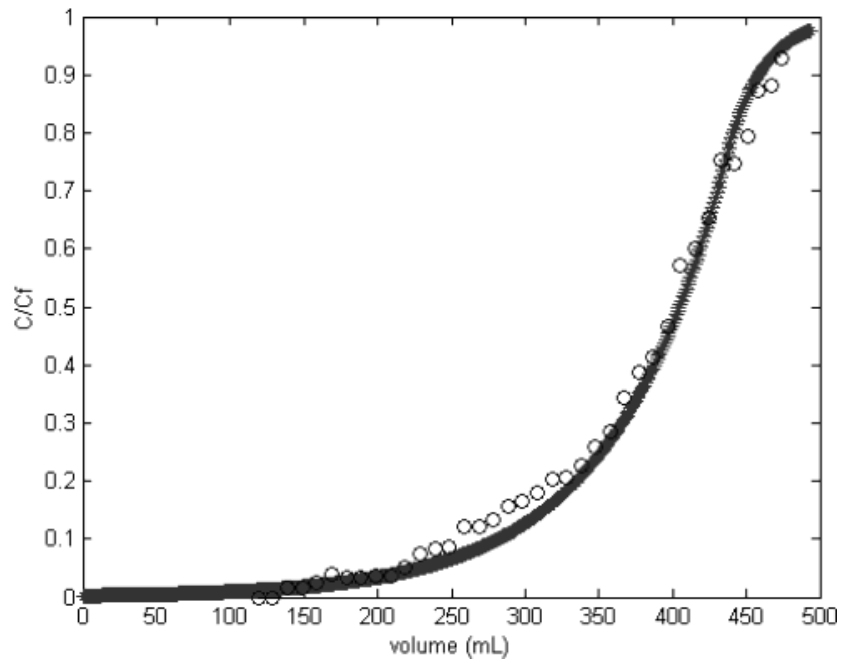

Figure 3. Comparison of experimental and predicted breakthrough curves for different column lengths ( $L$ ) and different mobile phase velocities $(u)(D=1.1 \mathrm{~cm})$. The markers $(O)$ represent experimental data points, and the solid lines represent simulated curves. The feed was harvested cell culture fluid having a protein concentration $\left(\mathrm{C}_{0}\right)$ of $0.5 \mathrm{mg} / \mathrm{mL}$. (a) $\mathrm{L}=11.5$ $\mathrm{cm} ; \mathrm{u}=120 \mathrm{~cm} / \mathrm{h}$. (b) $\mathrm{L}=6.0 \mathrm{~cm} ; \mathrm{u}=62 \mathrm{~cm} / \mathrm{h}$

in $25 \mathrm{mM}$ citrate ( $\mathrm{pH}$ 3.6). The media was regenerated using $100 \mathrm{mM}$ phosphoric acid.

Protein Analysis. Quantification of protein concentration was done using analytical Protein-A chromatography carried out on a POROS Protein-A $2.1 \mathrm{~mm} \times 30$ $\mathrm{mm}$ column. The column was equilibrated with a $25 \mathrm{mM}$ phosphate, $300 \mathrm{mM} \mathrm{NaCl}$, pH 7.2 buffer and eluted with $25 \mathrm{mM}$ phosphate, $300 \mathrm{mM} \mathrm{NaCl}$, pH 3.0 buffer. A flowrate of $1 \mathrm{~mL} / \mathrm{min}$ and UV detection at $280 \mathrm{~nm}$ was employed. The samples were injected directly, and the injection volume was adjusted accordingly (between 10 and $100 \mu \mathrm{L}$ ) to be within the linear range of the assay $(0-100 \mu \mathrm{g})$.

\section{Results and Discussion}

Determination of Parameters. Determination of Equilibrium Parameters. The Langmuir isotherm (eq 1) was used to fit the adsorption data of the Fc-fusion protein on MAb Select. The experimental data points and the theoretical fit along with the fitted parameters are shown in Figure 1. As seen in the figure, the isotherm is fairly rectangular with the stationary phase saturating 

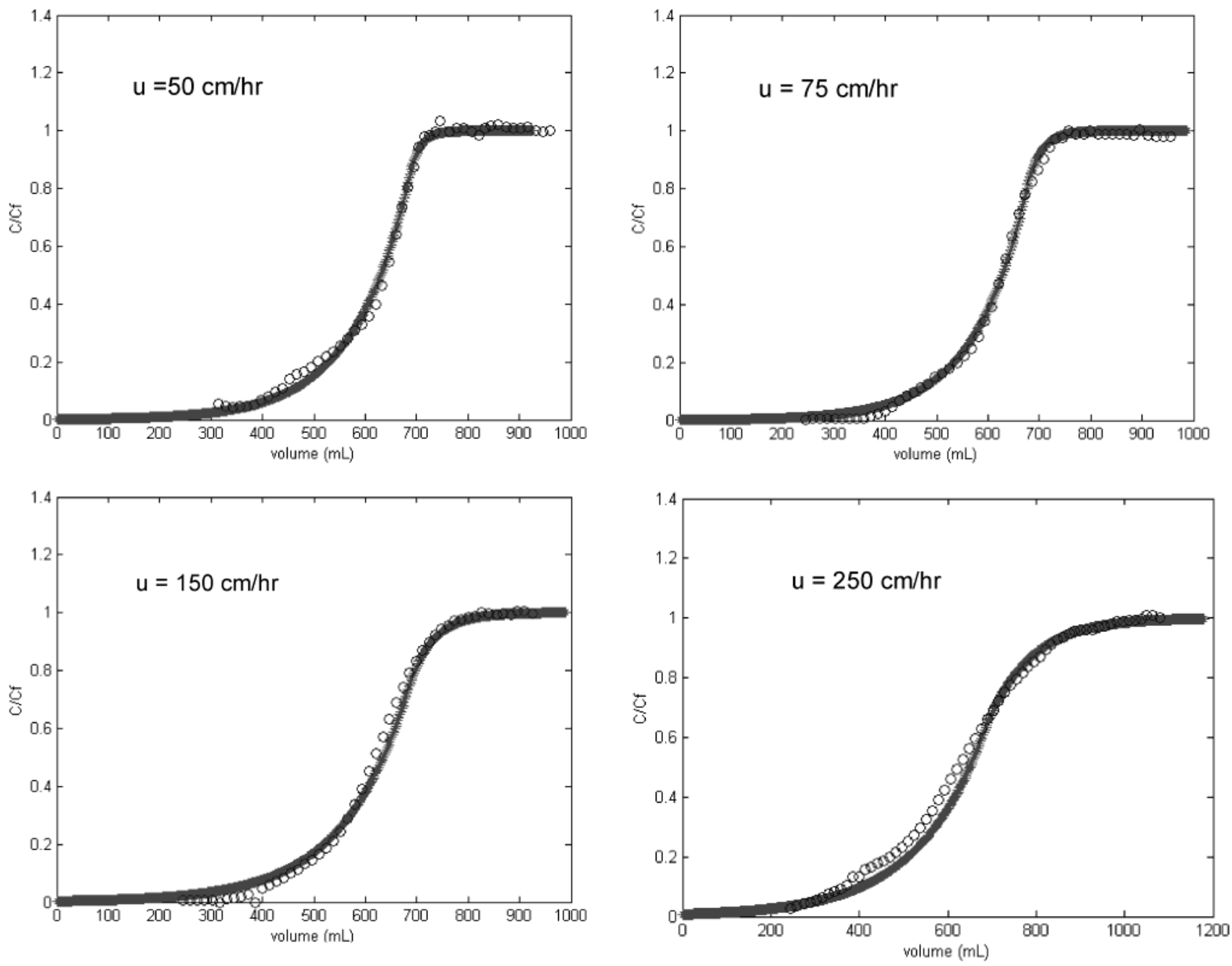

Figure 4. Comparison of experimental and predicted breakthrough curves for different single flowrates (u) at a fixed column length $(\mathrm{L}=11.5 \mathrm{~cm})$. All other conditions are same as in Figure 3.

at mobile phase protein concentrations $\geq 0.35 \mathrm{mg} / \mathrm{mL}$. $\mathrm{q}_{0}$ (obtained from the fit to be $36 \mathrm{mg} / \mathrm{mL}$ ) represents the saturation capacity of the Fc-fusion protein on MabSelect Protein-A media at equilibrium.

Determination of Transport Parameters $\left(D_{s}\right.$ and $\mathbf{k}_{\mathbf{f}}$ ). Figure 2a shows the stirred tank adsorption kinetic data measured using three different initial protein solution concentrations. From the figure it can be seen that the adsorption rate increases with increasing initial protein concentration and that equilibrium saturation is reached only at the higher mobile phase protein concentration of $2.6 \mathrm{mg} / \mathrm{mL}$. The uptake curves for higher protein concentration ( $>2.6 \mathrm{mg} / \mathrm{mL}$ ) did overlap with the uptake curve at $2.6 \mathrm{mg} / \mathrm{mL}$ (data not shown). Such behavior in adsorption kinetics has also been reported by previous authors $(12,22,23)$ and has been explained in terms of the homogeneous diffusion model. Because saturation capacity is reached at the higher mobile phase concentration, it can be assumed that the uptake rate is independent of the solution concentration at higher concentrations (as explained in Theory). Under these conditions, $\delta \gg 1$, and this falls in the diffusion controlled regime.

Thus, the experimental kinetics data at $\mathrm{C}=2.6 \mathrm{mg} /$ $\mathrm{mL}$ can be considered to be in the diffusion-controlled regime and was used to fit the effective diffusivity using eq 5 as shown in Figure $2 b$. The value of diffusivity $\left(D_{s}\right)$ obtained from the fit was $0.8 \times 10^{-9} \mathrm{~cm}^{2} / \mathrm{s}$ for the $\mathrm{Fc}$ fusion protein on MabSelect media. This value is in the same range as reported by other authors. McCue et al. (12) have reported $D_{s}$ values in the range of $0.3-5.0 \times$ $10^{-9} \mathrm{~cm}^{2} / \mathrm{s}$ for $\mathrm{hlgG}$ on porous glass based Protein-A media.

The film mass transfer coefficient $\left(\mathrm{k}_{\mathrm{f}}\right)$ at different linear flow vel ocities was found using eq 6 . Values of $\mathrm{k}_{\mathrm{f}}$ obtained were in the range of ca. $0.2-2.0 \times 10^{-4} \mathrm{~cm} / \mathrm{s}$ depending on the value of linear velocity chosen.

Validation of Model for Predicting Breakthrough Behavior. After determining the equilibrium and transport parameters, experimental breakthrough profiles were compared to theoretically calculated curves using the homogeneous diffusion model described in Theory. As the isotherm was found to be fairly rectangular in the concentration range being used, the analytical solution (eqs 8 and 9) was used for the calculation of the breakthrough curves. A value of $\epsilon=0.38$ (determined independently) was used for all calculations.

Figure 3 ( $a$ and $b$ ) shows the breakthrough curves of the F c-fusion protein for two different column lengths at a column residence time of six minutes. The exact details of each figure are given in the figure legends. The theoretically calculated breakthrough curves are overlaid on the same figure and show a good fit to the experimental data.

Further experiments were carried out to validate the model for successfully predicting breakthrough behavior (and therefore capacity) over a wide range of velocities. Figure 4 shows simulation vs experimental data for 
(a)

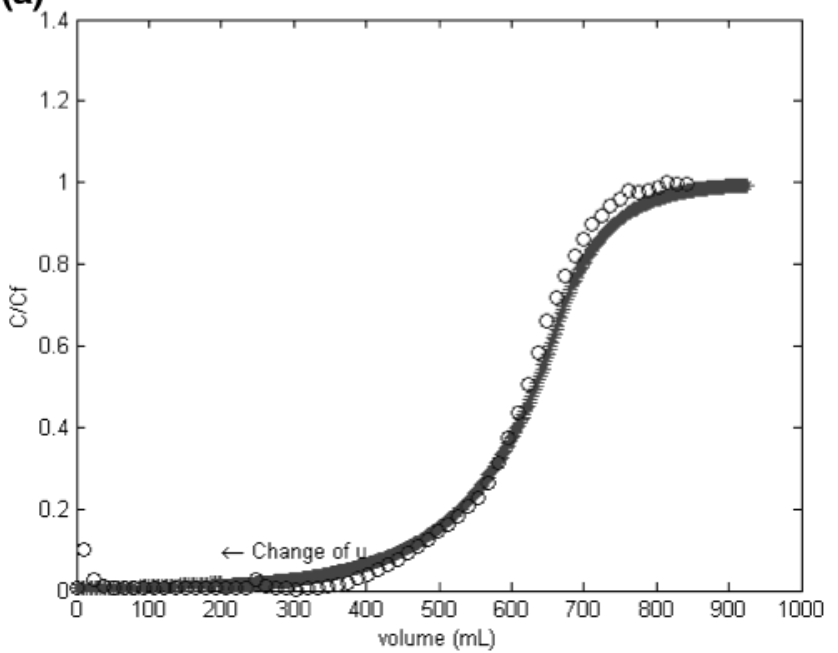

(b)

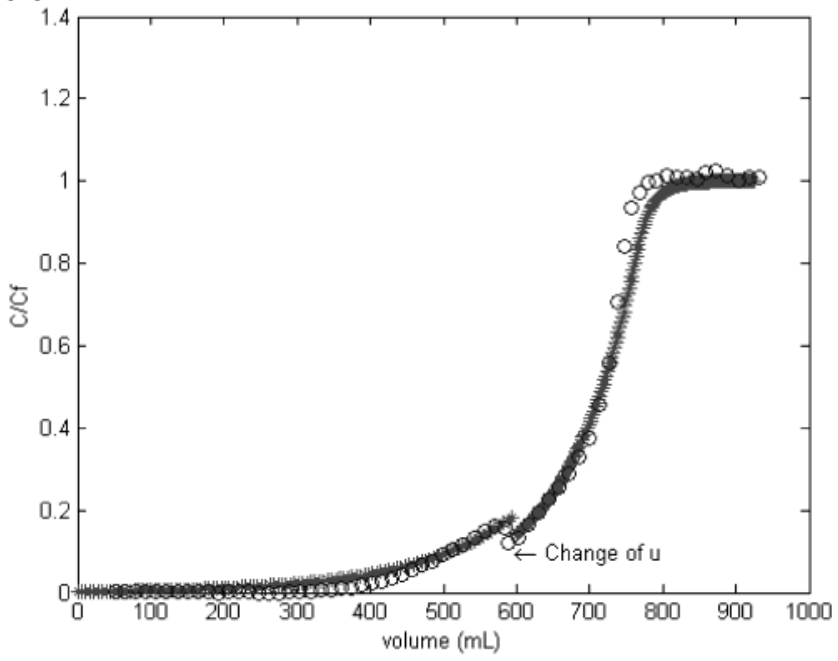

Figure 5. Comparison of experimental and predicted breakthrough curves for different combinations of dual flowrates at a fixed column length $(\mathrm{L}=11.5 \mathrm{~cm})$. All other conditions are same as before. (a) $u_{1}=200 \mathrm{~cm} / \mathrm{h}, u_{2}=100 \mathrm{~cm} / \mathrm{h}, \mathrm{t}_{\mathrm{seg}}=63.25$ $\min \left(\right.$ i.e., $V_{\mathrm{seg}}=200 \mathrm{~mL}$ ). (b) $u_{1}=150 \mathrm{~cm} / \mathrm{h}, u_{2}=50 \mathrm{~cm} / \mathrm{h}, \mathrm{t}_{\mathrm{seg}}=$ $250 \mathrm{~min}$ (i.e., $\mathrm{V}_{\mathrm{seg}}=594 \mathrm{~mL}$ )

frontal curves generated over a range of linear velocities $(50-250 \mathrm{~cm} / \mathrm{h})$. As seen in the figure this relatively simplistic model provides good predictions of the experimental breakthrough curves for a range of flowrates.

While the model is well suited for predicting experiments using a single flowrate during the loading step, it is important to validate the model for the two-step loading strategy when the flowrate is changed from a higher value $\left(\mathrm{u}_{1}\right)$ to a lower value $\left(\mathrm{u}_{2}\right)$ at an intermediate time $\left(\mathrm{t}_{\text {seg }}\right)$ during loading. Figure $5(\mathrm{a}$ and $\mathrm{b})$ shows simulation and experimental data for two breakthrough experiments done with two different combinations of $u_{1}$,

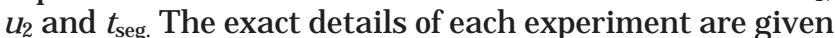
in the figure legends. Figure 5a shows a case study where the flowrate is changed quite early during the loading process, whereas Figure $5 \mathrm{~b}$ represents a situation where the second flowrate is applied well after 5\% breakthrough has occurred with the initial flowrate. As can be seen in the figure, there is a discontinuity in the breakthrough profile after the switch in flowrate is made. This is because the second (lower) flowrate enables binding on stationary phase sites that were less accessible at the higher flowrate. This causes a slight decrease in the outlet concentration of the protein as a greater proportion

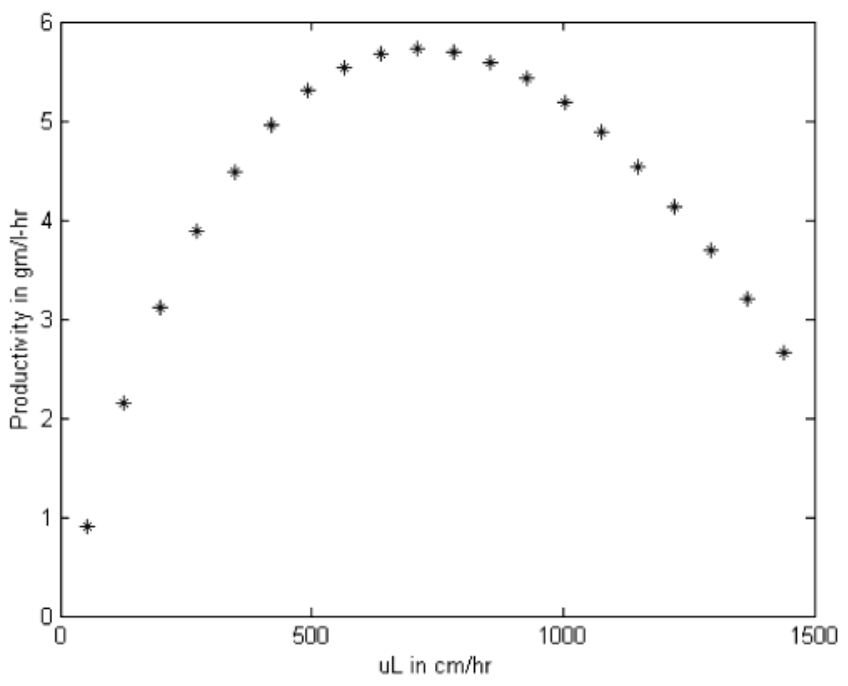

Figure 6. Simulated plot of productivity vs linear loading velocity for the single-flowrate case. The values of other parameters chosen are $\mathrm{L}=25 \mathrm{~cm}, \mathrm{D}=45 \mathrm{~cm}, \mathrm{C}_{0}=0.5 \mathrm{~g} / \mathrm{L}, \mathrm{N}$ $=10, \mathrm{u}_{\mathrm{N}}=200 \mathrm{~cm} / \mathrm{h}$.

of the incoming protein now binds to the column. This discontinuity can be more readily visualized in cases where the switch is made after some breakthrough has al ready occurred (Figure 5b). From these figures, it is clear that the model is able to capture the breakthrough behavior under these limiting two-flowrate scenarios.

Clearly, the analytical solution used here is successfully able to capture breakthrough behavior over a wide variety of operating conditions. For all of the breakthrough experiments, the experimental capacity at 5\% breakthrough was compared to the theoretically calculated and was found to be well within a $\pm 10 \%$ experimental error. In the next section of the paper, the model is used to calculate the $5 \%$ breakthrough capacity $\left(Q_{d}\right)$ that is employed in the optimization routine.

Optimization of Throughput and Comparison of Loading Strategies. Comparison of Productivity. To compare the two loading strategies, productivity values were calculated at different loading vel ocities for both the single-flowrate and dual-flowrate cases and the optimum values for each case were compared. Parametric plots were also generated in order to visualize the variation of productivity $(P)$ with respect to the load velocity $(u)$. Figure 6 shows a plot of productivity vs linear loading velocity $(u)$ for the single-flowrate case. As seen in the figure, productivity at first increases with increasing $u$ (due to a reduction in loading time) and then decreases at higher $u$ values (due to the decrease in column dynamic capacity, which outweighs any advantages obtained from the lower loading time). Clearly, an optimum loading velocity exists when only a single flowrate is used for loading.

When two flowrates are employed during loading, there are three separate variables: the initial loading velocity $\left(u_{1}\right)$, the loading velocity after the switch in flowrates is made $\left(u_{2}, u_{1}>u_{2}\right)$ and the time at which the switch is made $\left(t_{\text {seg }}\right)$. Accordingly, a set of 3-dimensional plots with $\mathrm{u}_{1}$ and $\mathrm{u}_{2}$ al ong the $\mathrm{x}$ and $\mathrm{y}$ axes and productivity on the $z$-axis can be made for each value of $t_{\text {seg. }}$. A set of three such figures are shown in Figure $7 \mathrm{a}, \mathrm{b}$ and $\mathrm{c}$ for a high, moderate and low value of $t_{\text {seg, }}$, respectively. As seen from the figures, if $u_{1}$ or $u_{2}$ are held constant the productivity curve would be similar in form to Figure 6 . However if both $\mathrm{u}_{1}$ and $\mathrm{u}_{2}$ are allowed to vary, an optimum exists for a particular combination of $u_{1}$ and $u_{2}$ at each value 


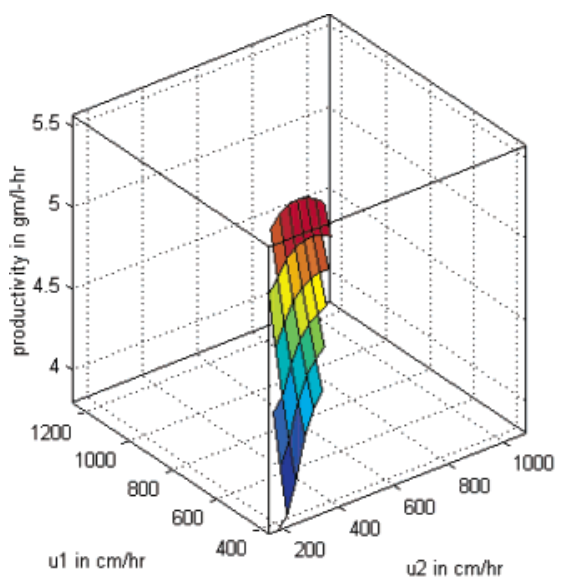

(a)

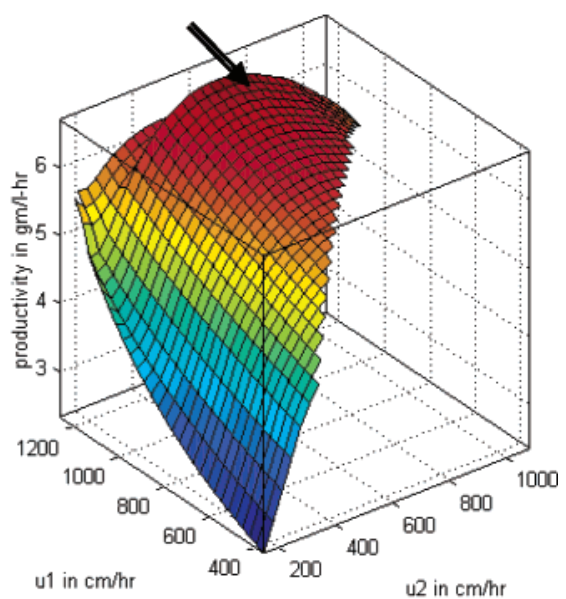

(b)

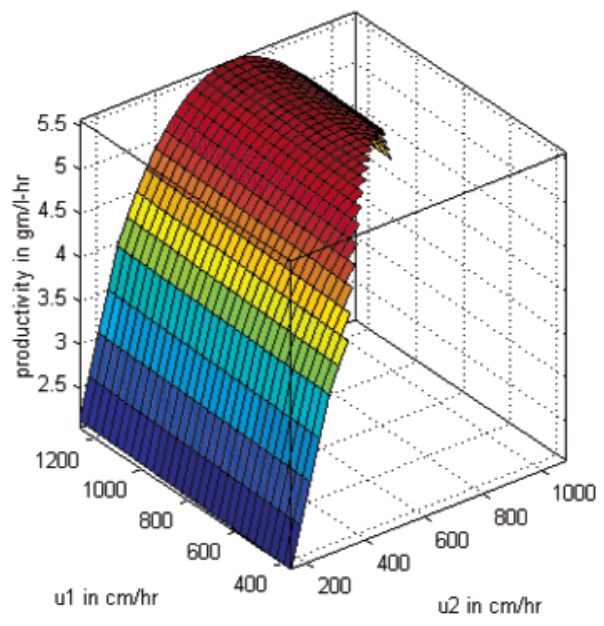

(c)

Figure 7. Simulated plot of productivity vs the two loading velocities $\left(u_{1}\right.$ and $u_{2}$ ) at a particular $t_{\text {seg }}$ for the dual-flowrate case. (a) $t_{\text {seg }}=5000 \mathrm{~s}$. (b) $t_{\text {seg }}=1298 \mathrm{~s}$. (c) $t_{\text {seg }}=500 \mathrm{~s}$. The values of the other operating parameters are the same as in Figure 6.

of $t_{\text {seg. }}$ F or a high value of $t_{\text {seg }}($ Figure $7 a)$, breakthrough can occur even before the switch in flowrates is made, thus restricting the area of the surface. Thus, if the switch is made too late, no advantage results from the strategy of employing two fl owrates. On the other hand, if the switch is made too early (Figure 7c), the loading time saved by making the switch is not significant. The highest value of productivity is obtained at the intermediate $t_{\text {seg }}$ value (Figure $7 b$ ). A particular combination of $\mathrm{u}_{1}, \mathrm{u}_{2}$ and $\mathrm{t}_{\mathrm{seg}}$ will give the global optimum for productivity.

The optimization routine described in the theory section was used to obtain the global optimum. Table 1 shows the optimization results for both the singleflowrate and dual-flowrate loading strategies. As can be seen from the table, the dual-flowrate strategy resulted in $a \sim 15 \%$ improvement in productivity. The combination of $u_{1}, u_{2}$ and $t_{\text {seg }}$ that resulted in this optimum value is shown by the arrow in Figure $7 b$ which was generated using the optimal value of $\mathrm{t}_{\text {seg. }}$.

Comparison of Loading Time. Sometimes in a manufacturing operation it may not be prudent to operate at the point of highest productivity alone. Protein-A resins are typically very expensive and have a finite lifetime (usually 100 cycles); hence operating at the highest productivity might mean that the resin binding capacity is not utilized to its fullest extent. Although using a very slow loading flowrate would give the maximum resin utilization, such an approach is obviously not desirable from a production time point of view.
Table 1. Optimization Results for the Case Study $L=25$ $\mathrm{cm}, \mathrm{C}_{0}=0.5 \mathrm{~g} / \mathrm{L}$

\begin{tabular}{llc}
\hline \multicolumn{1}{c}{$\begin{array}{c}\text { loading } \\
\text { strategy }\end{array}$} & \multicolumn{1}{c}{$\begin{array}{c}\text { optimum } \\
\text { operating parameters }\end{array}$} & $\begin{array}{c}\text { optimum } \\
\text { production rate }\end{array}$ \\
\hline single flowrate & $\mathrm{u}=0.21 \mathrm{~cm} / \mathrm{s}(756 \mathrm{~cm} / \mathrm{h})$ & $5.5 \mathrm{~g} / \mathrm{L}-\mathrm{h}$ \\
dual flowrate & $\mathrm{u}_{1}=0.3 \mathrm{~cm} / \mathrm{s}(1080 \mathrm{~cm} / \mathrm{h})$ & $6.4 \mathrm{~g} / \mathrm{L}-\mathrm{h}$ \\
& $\mathrm{u}_{2}=0.2 \mathrm{~cm} / \mathrm{s}(720 \mathrm{~cm} / \mathrm{h})$ & \\
& $\mathrm{t}_{\mathrm{seg}}=1298 \mathrm{~s}$ &
\end{tabular}

Conventionally, a rule of thumb in industrial Protein-A operation is to use a single loading flowrate that results in a col umn residence time of 5-6 min for loading (9). In fact, the best strategy in many cases would be to maximize loading capacity while making sure productivity is adequate and does not make downstream purification the rate-limiting step in the process. Thus, it would be advantageous if by using the dual-flowrate strategy one could obtain the same binding capacity with a significant decrease in the loading time.

Figure 8 shows an overlay of two experimental breakthrough curves, one obtained by using a single loading flowrate corresponding to a column residence time of 6 min and the other obtained by using the dual-flowrate strategy. F or the latter, the values of $u_{1}, u_{2}$ and $t_{\text {seg }}$ were obtained theoretically such that it would result in a similar capacity to the single-u case. The values of these operating parameters are listed in the figure legend. As seen in the figure, the two curves virtually coincide, resulting in the same dynamic capacity on the column. However, the loading time to $5 \%$ breakthrough is sig- 


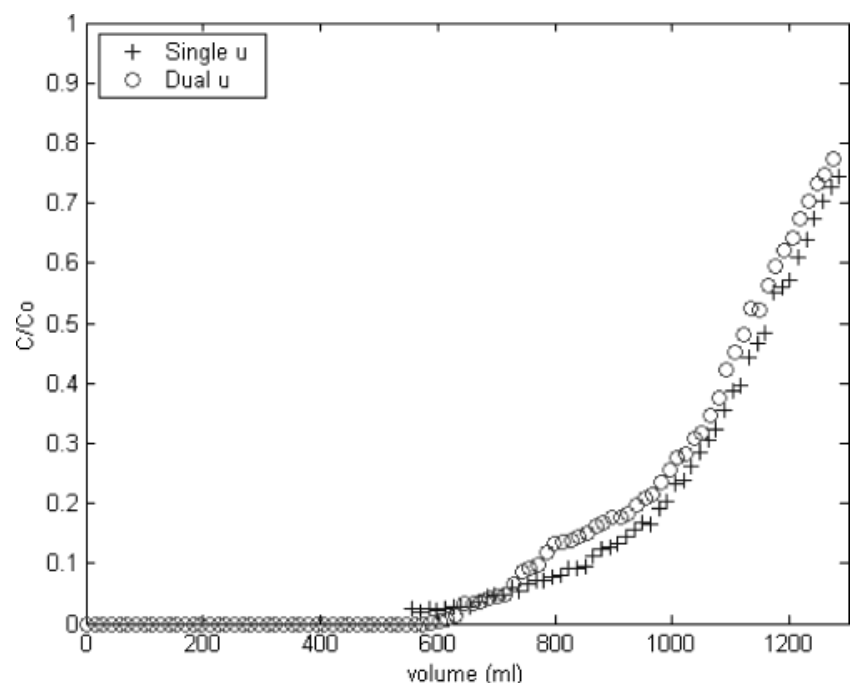

Figure 8. Overlay of experimental breakthrough curves obtained with the single-flowrate and dual-flowrate strategy for $\mathrm{L}=18 \mathrm{~cm}, \mathrm{D}=1.1 \mathrm{~cm}, \mathrm{C}_{0}=0.5 \mathrm{~g} / \mathrm{L}$. For single flowrate $\mathrm{u}=$ $180 \mathrm{~cm} / \mathrm{h}$; for the dual-flowrate case $\mathrm{u}_{1}=360 \mathrm{~cm} / \mathrm{h}, \mathrm{u}_{2}=180$ $\mathrm{cm} / \mathrm{h}, \mathrm{t}_{\mathrm{seg}}=2750 \mathrm{~s}$ (i.e., $\mathrm{V}_{\mathrm{seg}}=261.25 \mathrm{~mL}$ ).

nificantly higher when using a single flowrate (256.7 min) as compared to the dual flowrate (203.55 min). This would result in approximately a $25 \%$ decrease in loading time while still delivering the same binding capacity. Clearly, the dual-flowrate loading strategy is once again advantageous in that it allows one to maintain column binding capacity (and hence similar resin costs) while improving process productivity.

Simultaneous Optimization of Productivity and Capacity. In fact, it would be most desirable to simultaneously optimize both productivity and capacity. However, as explained above, these two objectives are at odds with each other since optimizing one objective alone automatically puts the other at a disadvantage. To address this, an additive weighted combination of productivity and capacity (eq 14) was employed as the objective function to find the optimal combination of $u_{1}$, $\mathrm{u}_{2}$ and $\mathrm{t}_{\mathrm{seg}}$ and to compare the results with the singleflowrate scenario. Figure 9 shows a plot of optimal productivity vs optimal capacity compared for the singleand dual-flowrate strategies. Each point on the curve for the dual-flowrate case corresponds to a unique combination of $u_{1}, u_{2}$ and $t_{\text {seg }}$ and a particular weighting factor. Weighting factors (productivity/capacity) ranging from 0.4 to 1.0 were used for generating the curve. Weighted factors lower than 0.3 were not plotted, as they were found to give an undue large weight to capacity and hence made the objective function a monotonically decreasing function of flowrate, rendering optimization redundant. Each point on the single-flowrate curve corresponds to an optimal value of $u$ for a particular weighting factor. The curve represents the highest productivity that can be obtained for a given binding capacity (and vice versa). By moving along the curve, one can select the operating conditions that give the user discretion over what combination of binding capacity and productivity are desirable for a particular industrial situation. This curve can be very useful in designing Protein-A processes for specific applications and can readily be interfaced with other algorithms that can calculate operating costs and take facility constraints into account. The figure emphasizes the tradeoff between productivity and capacity. In addition, it can be seen that the dual-flowrate curve is higher than that obtained for thesingleflowrate. Clearly,

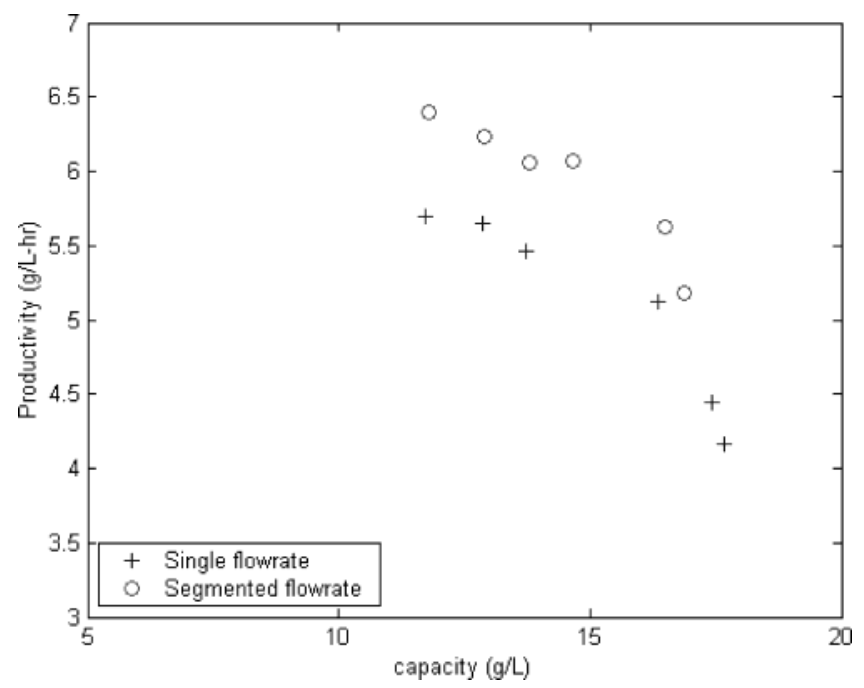

Figure 9. Plot of optimal productivity vs optimal capacity (at a particular weighting factor) for the single- and dual-flowrate loading strategy. Simulations were done taking the same parameters as in Figures 6 and 7.

the dual-flowrate loading process is superior to the singleflowrate process, resulting in simultaneously higher productivity and capacity.

\section{Conclusions}

With the increasingly important niche that monoclonal antibodies have come to occupy in the biopharmaceutical industry, there is a pressing need for the development of efficient, robust and cost-effective downstream processes. Currently, Protein-A is the key step for almost all F c-fusion protein and antibody purification processes. However, this unit operation is also the most costly and time-consuming step in the overall process, and any improvement in the throughput of this step would have a significant effect on the overall process efficiency. This paper demonstrates a methodology that can yield higher throughput in Protein-A systems by use of a dualflowrate loading strategy in contrast to the singleflowrate regimen that is typically employed.

The effect of such a strategy was captured theoretically by the use of a chromatographic model that was able to simulate breakthrough curves for our Protein-A system. This model uses readily measurable adsorption parameters from equilibrium measurements and intraparticle transport parameters obtained from stirred-tank experiments.

The dual-flowrate strategy was found to have significant advantages over the typical single flowrate used for Protein-A column loading. When both of these strategies were independently optimized, the use of a dual flowrate was found to yield a significant improvement in process throughput. In addition, for scenarios where maintaining a specific column capacity is important for cost reasons, the dual-flowrate loading was shown to reduce column loading time and thus increase throughput.

In another extension of this work, a weighted combination of loading capacity and productivity were optimized to give the user flexibility in selecting the optimal combination that would be the best fit the process based on facility scheduling or economic constraints. The simultaneous optimization of capacity and throughput offers a very useful and readily usable tool for Protein-A process design. In addition, this approach also emphasized the superiority of the dual stepped loading flowrates over a single flowrate in enabling simultaneously higher productivity and capacity. 
This work has examined a two-step loading strategy since this minor change in operating procedure can be readily implemented at the manufacturing scale. An interesting extension of this work would be to employ a multistep flowrate change or a continuous function where flowrate changes continuously with time. Clearly, this would involve either more computationally expensive simulations (more parameters to be optimized) or more complicated equipment skids in the manufacturing settings. In addition, this strategy can be expected to have the greatest advantage for resins with steep capacity versus flowrate relationships over the ones with a shallower curve. It should be interesting to examine the relative process improvements that could be achieved on various Protein-A stationary phases using this two-step loading strategy.

\section{Notation}

A column cross-sectional area

b affinity coefficient in Langmuir isotherm

C solution concentration of protein

C* solution concentration of protein at equilibrium

$\mathrm{C}_{\mathrm{i}} \quad$ solution concentration of protein at particle surface

$\mathrm{C}_{0}$ initial protein concentration in solution or feed concentration

$d_{p} \quad$ particle diameter

$D_{a} \quad$ axial dispersion coefficient

$D_{m}$ molecular diffusivity in free aqueous solution

$D_{s} \quad$ intraparticle diffusivity

$\mathrm{N}$ number of column volumes of nonload buffers passed over the column. (It is to be noted that the time for a cycle consists of the time for loading the feed material and the time for all nonload steps, which include equilibration, wash and elution.)

$\mathrm{k}_{\mathrm{f}} \quad$ external film mass transfer coefficient

L column length

q stationary phase protein concentration

$q^{*} \quad$ stationary phase protein concentration at equilibrium

$\bar{q}$ average protein concentration on the stationary phase

qo maximum adsorption capacity in Langmuir isotherm

$\mathrm{Q}_{\mathrm{d}}$ dynamic capacity at 5\% breakthrough (taken as the surrogate for column loading)

$r$ radial particle coordinate

$\mathrm{R}_{\mathrm{p}} \quad$ particle radius

$t$ time

$t_{\text {seg }}$ time at which the switch in flowrates is done for the dual flowrate loading strategy

u superficial velocity

$\mathrm{u}_{\mathrm{L}} \quad$ linear velocity during column loading for single flowrate loading strategy

$\mathrm{u}_{1} \quad$ initial flowrate during column loading for dual flowrate loading strategy

$\mathrm{u}_{2}$ later flowrate during column loading for dual flowrate loading strategy

$u_{N} \quad$ linear velocity for the nonload steps in the process (all nonload steps assumed to have the same flowrate)

$\mathrm{V}$ column volume

$V_{M} \quad$ volume of sorbent

z axial distance coordinate

Greeks

$\delta \quad$ parameter defined by eq 4 kinematic viscosity extraparticle void fraction parameter defined by eq 9 viscosity of the solution density of the solution parameter defined by eq 9

\section{References and Notes}

(1) Pharmaceutical Research and Manufacturers Association; Survey of biopharmaceuticals in development 2000 (http://www.phrma.org/searchcures/newmeds/biotech2000/ bio00.pdf).

(2) Blank, G. Affinity purification of polypeptide on Protein-A matrix. U.S. Patent WO 9823645, 1996.

(3) Kagel, R. A.; Kagel, G. W.; Garg, V. K. High performance protein A and immuno-affinity chromatography for the commercial purification of anti-human tissue plasminogen activator. BioChromatography 1989, 4(5), 246-252.

(4) Fahrner, R. L.; Knudsen, H. L.; Basey, C. D.; Galan, W.; Feuerhelm, D.; Vanderlaan, M.; Blank, G. S. Industrial purification of pharmaceutical antibodies: Development, operation, and validation of chromatography processes. Biotechnol. Genet. Eng. Rev. 2001, 18, 301-327.

(5) J andera, P.; Komers, D.; Guichon, G. Effects of the gradient profile on the production rate in reversed-phase gradient elution overload chromatography. J . Chromatogr., A 1997 760, 25-39.

(6) Fahrner, R. L.; Whitney D. H.; Vanderlaan, M.; Blank, G. S. Performance comparison of Protein-A affinity chromatography sorbents for purifying recombinant monoclonal antibodies. Biotechnol. Appl. Biochem. 1999, 30, 121-128.

(7) Fahrner, R. L.; Iyer, H. V.; Blank G. S. The optimal flow rate and column length for maximum production rate of protein A affinity chromatography. Bioprocess Eng. 1999, 21, 287-292.

(8) Iyer, H.; Henderson, F.; Cunningham, E.; Webb, J .; Hanson, J .; Bork, C.; Conley, L. Considerations during development of a Protein-A based antibody purification process. BioPharm. 2002, J an, 14-20.

(9) Shukla, A. A.; Hinckley, P. H.; Hubbard, B. Productivity comparisons on Protein-A affinity chromatography. Presented at ACS National Meeting, Boston, 2002.

(10) Horstmann, B. J .; Chase, H. A. Modeling the affinity adsorption of immunoglobulin $\mathrm{G}$ to Protein-A immobilized to agarose matrixes. Chem. Eng. Res. Des. 1989, 67(3), 243254.

(11) Montesinos, R. M.; Guzman, R.; Tejeda-Mansir, A. Simulation of stirred tank affinity processes applied to separation of proteins. Int. J . Bio-Chromatogr. 2001, 6(3), 231-243.

(12) McCue, J. T.; Kemp, G.; Low, D.; Quinones-Garcia, I. Evaluation of Protein-A chromatography media. J . Chromatogr., A 2003, 989, 139-153.

(13) Felinger, A.; Guiochon, G. Optimizing experimental conditions for minimum production cost in preparative chromatography. AIChE J . 1994, 40, 594-605.

(14) Felinger, A.; Guiochon, G. Optimizing experimental conditions in overloaded gradient elution chromatography. Biotechnol. Prog. 1996, 12, 638-644.

(15) Luo, R. G.; Hsu, J . T. Optimization of gradient profiles in ion-exchange chromatography for protein purification. Ind. Eng. Chem. Res. 1997, 36, 444-450.

(16) Gallant, S. R.; Kundu, A.; Cramer, S. M. Optimization of step gradient separations: Consideration of nonlinear adsorption. Biotechnol. Bioeng. 1995, 47(3), 355-372.

(17) Gallant, S. R.; Vunnum, S.; Cramer, S. M. Optimization of preparative ion-exchange chromatography of proteins: Linear gradient separations. J . Chromatogr., A 1996, 725(2), 295-314.

(18) Natarajan, V.; Cramer, S. M. Optimization of ion-exchange displacement separations II. Comparison of displacement separations on various ion-exchange resins. J . Chromatogr., A 2000, 876(1-2), 63-73.

(19) Suwondo, E.; Wilhelm, A. E.; Pibouleau, L.; Domenech, S. Optimization of a liquid chromatographic separation process. Comput. Chem. Eng. 1993, 17, S135-S140.

(20) Nagrath, D.; Messac, A.; Bequette, B. W.; Cramer, S. M. A Hybrid model framework for the optimization of preparative chromatgraphic processes. Submitted for publication

(21) J ohansson, H.; Lacki, C. Novel approach to increased productivity and functional lifetime of Protein A resins. Presented at IBC Antibody Production \& Downstream Processing meeting, September 24, 2002. 
(22) Weaver, L. E., J r.; Carta, G. Protein adsorption on cation exchangers: Comparison of macroporous and gel-composite media. Biotechnol. Prog. 1996, 12, 342-355.

(23) Fernandez, M. A.; Carta, G. Characterization of protein adsorption by composite silica-polyacrylamide gel anion exchangers: I. Equilibrium and mass transfer in agitated contactors. J . Chromatogr., A 1996, 746, 169-183.

(24) Fernandez, M. A.; Laughinghouse, W. S.; Carta, G. Characterization of protein adsorption by composite silica-polyacrylamide gel anion exchangers: II. Mass Transfer in packed columns and predictability of breakthrough behavior. J. Chromatogr., A 1996, 746, 185-198.

(25) Helfferich, F.; Plesset, M. S. I on-exchange kinetics: A nonlinear diffusion problem. J . Chem. Phys. 1958, 28, 418424.
(26) Helfferich, F. I on Exchange; Mc-Graw Hill: New York, 1962; pp 255-260.

(27) Foo, S. C.; Rice, R. G. Prediction of ultimate separation in parametric pumps. AIChE J . 1975, 21(6), 1149-1158.

(28) Tyn, M. T.; Gusek, T. W. Prediction of diffusion coefficients of proteins. Biotechnol. Bioeng. 1990, 35(4), 327-38.

(29) Yoshida, H.; Kataoka, T.; Ruthven, D. M. Analytical solution of the breakthrough curve for rectangular isotherm systems. Chem. Eng. Sci. 1984, 39(10), 1489-1497.

Accepted for publication December 10, 2003.

BP0342654 